\title{
The architectural and acoustic quality for theatres hosting animals
}

Cite as: AIP Conference Proceedings 2307, 020033 (2020); https://doi.org/10.1063/5.0032654

Published Online: 15 December 2020

Maria Cairoli, and Lamberto Tronchin

\section{ARTICLES YOU MAY BE INTERESTED IN}

The water bodies in the Southern East of Iraq before and after 2018

AIP Conference Proceedings 2307, 020032 (2020); https://doi.org/10.1063/5.0033124

Analysis and simulation of four-wheel independent steering control for electric vehicles

AIP Conference Proceedings 2307, 020046 (2020); https://doi.org/10.1063/5.0035180

Assessment of API pipeline steel surface and its environmental vulnerability

AIP Conference Proceedings 2307, 020040 (2020); https://doi.org/10.1063/5.0033735

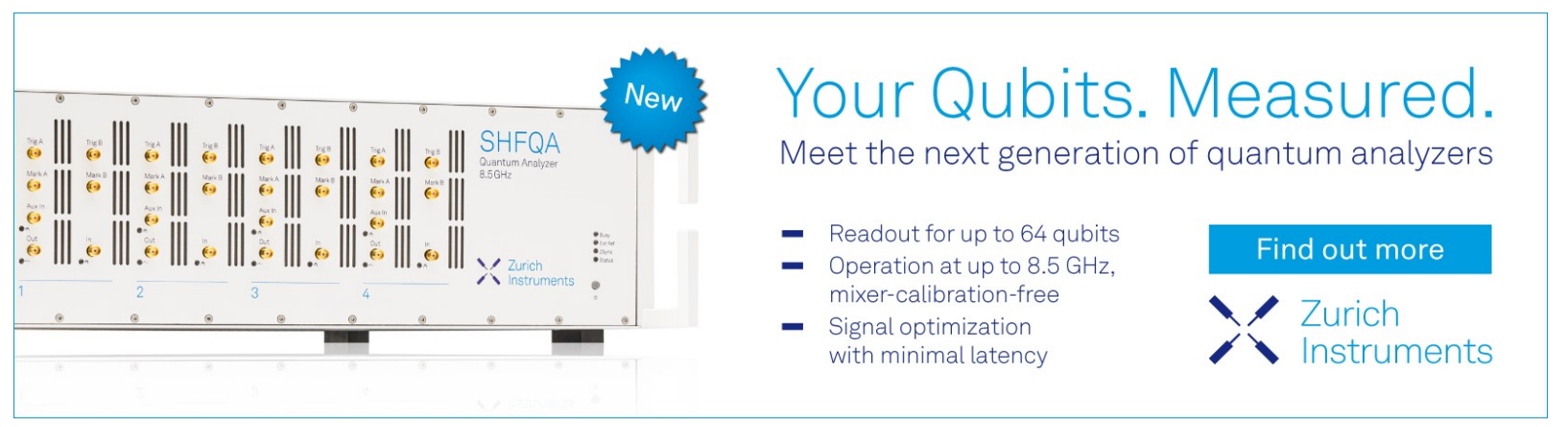




\title{
The Architectural and Acoustic Quality for Theatres Hosting Animals
}

\author{
Maria Cairoli $^{1, \text { a) }}$ and Lamberto Tronchin ${ }^{2, \text { b) }}$ \\ ${ }^{1}$ Politecnico di Milano, via Lambruschini 5- Milano, Italy \\ ${ }^{2}$ DA-CIARM, University of Bologna, Via dell'Università 5047521 Cesena (FC), Italy \\ a) maria.cairoli@polimi.it \\ b)lamberto.tronchin@unibo.it
}

Corresponding Author: lamberto.tronchin@unibo.it

\begin{abstract}
The paper investigates the optimal acoustic characteristics for theatres that include animals in their shows, especially horses, seeking for the maximum comfort both for people and for animals. Recommendations and indications might become guidelines for a possible architectural acoustic design. The architectural elements to influence the room acoustic response are indicated and numerous objective parameters to identify and describe the trend of the requested sound field are described. Having considered a good acoustic field for animals when the early reflections are usually present but late reflections are rare, the Reverberation Time at middle frequencies is introduced. The range of frequencies is extended from 63 to $8000 \mathrm{~Hz}$. In the paper it is reported that optimal acoustic conditions are reached when the gross volume of the theatre should not exceed approximately $1800 \mathrm{~m}^{3}$, with high level of intelligibility (more than $60 \%$ ) and Early Decay Time of $1.1 \mathrm{~s}$. The interest to design theatres to host animals arises from some existing buildings which seldom host animal shows together with musical performances, which represents a hybrid solution between theatres and circuses. These buildings might help especially young people having some mental disorders to improve their living quality. One example is represented by the Emilia Bosis Foundation in Verdello (Bergamo, Italy), a non-profit organization that deals with people with mental disorders, to develop a space where to set up projects that include arts, animals ( horses in particular), and other cultural and social activities.
\end{abstract}

\section{INTRODUCTION}

The research on the optimization of the environmental quality in rooms is an important issue that is normally achieved in important historical buildings (1) and for this reasons new methods and devices are often proposed (2), especially in the thermal technology (3), also by means of numerical (4) or statistical evaluations (5). Among them, the research about environmental and especially room acoustic quality in buildings -theatres- that host animals, is almost totally absent. This study comes from the request of the Emilia Bosis Foundation, a non-profit organization located in Bergamo, Northern Italy, that deals with people with mental disorders.

The objective of this paper is to develop some recommendations useful for designing a space where to carry out shows that use the arts, the relationship with animals, and other cultural and social activities, finding out a possible acoustic trend and guidelines for its architectural design. The Bosis community owns numerous animals, especially horses, that are the most used in their theatrical performances. For this reason, the identification of the guidelines for the architectural acoustic design of a theatre that includes animals, starts from a summary research on the voice of these equines.

The optimization of the room acoustic quality fulfills both the needs of the audience and of the animals. Great attention is given to the architectural aspects that influence the room acoustic behavior, for example the ratio between the volume and the seats' number, between the stage and the stall surfaces, the plan shape and the used materials.

A possible trend for the design on the optimization of the acoustic quality for theatres that host animals, is proposed in the concept design for the theatre "La Stalla"

Technologies and Materials for Renewable Energy, Environment and Sustainability AIP Conf. Proc. 2307, 020033-1-020033-6; https://doi.org/10.1063/5.0032654 Published by AIP Publishing. 978-0-7354-4043-2/\$30.00 
The chosen place for the theatre construction is Verdello, in the province of Bergamo (Italy), in the so-called "Cascina Germoglio", a kind of agricultural farm managed by the Foundation; the chosen name for the theatre is "Teatro Stalla" (i.e. stable theatre), a space for research and scenic representation. The idea of a very particular theatre is the result of a work done by artists, directors, sculptors, musicians, researchers and philosophers, to join different scenic experiences carried out by professionals, educators, in relation to the horses hosted by the community.

\section{THE VOICE OF HORSES}

The Bosis community owns numerous animals, especially horses, that are the most used in their theatrical performances. For this reason, the identification of the guidelines for the architectural acoustic design of a theatre that includes animals, starts from a summary research on the voice of these equines.

This theme is widely covered in the literature, especially because the study of acoustic variables related to horses' behavior increase the knowledge about the different species and help with their conservation.

Moreover, sound categorization plays a crucial role in processing ecological and social stimuli in a natural environment (6).

The horses' vocalizations can be analyzed by sound analysis software where acoustic parameters can be used for indicating an individual's physiological and emotional state. Horse vocalizations can provide information about the caller's sex, body size, identity, motivation, and physiological states $(7,8,9)$.

In equines, calls that are given by separated foals and mothers, or by stallions separated from their group, could also be classified as affiliative or separation calls, especially if a reunion followed these vocalizations (fig. 1).

Background noise is a very common problem that can affect the quality of the recordings. Therefore, only calls with low levels of background noise are usually included in the acoustic analysis.

The significant frequency range for the horses extends from very low frequencies to $8000 \mathrm{~Hz}$. The duration of a call might vary from 0.2 to 1.7 seconds, the Intensity from 30 to $55 \mathrm{~dB}$, the fundamental frequency $\mathrm{f}_{0}$ is around 350 $\mathrm{Hz}(10)$. Also the affective state of an individual can also be shown by the acoustic structure of their vocalization (11).

Designing a space for animals it is important to know and respect their natural environment, considering both the noise in nature and in the stable. Observing the horses' concision in Verdello it is deducted the animals remain quiet if the sound pressure level around them doesn't exceed roughly $75 \mathrm{~dB}$.

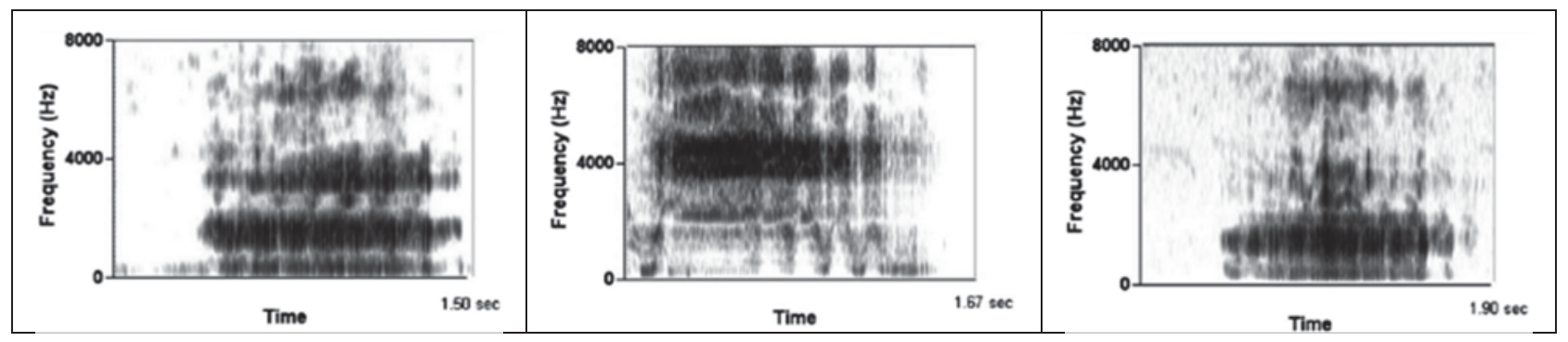

FIGURE 1. Example of spectrograms of separation calls produced by horses to identify the duration and the mean signals' frequencies (from left to right): a mare, a foal, a stallion (12). The mare voice has the widest range of frequencies, the main frequencies of the foal are higher than that of the stallion

\section{THE ACOUSTIC QUALITY TREND TO HOST ANIMALS}

The optimization of the room acoustic quality in such a kind of building, has to fulfill both the needs of the audience and of the animals. Great attention has to be given to the architectural aspects that influence the room acoustic behavior, for example the ratio between the volume and the seats' number, between the stage and the stall surfaces, the plan shape and the used materials (13).

The description of the sound field in this typology of space requires several objective parameters, which might be able to guarantee the desired comfort. The main parameters here proposed are already identified for other 
application in acoustics, including different types of buildings $(14,15,16,17)$. In this paper the specific optimal ranges for theatres to host animals are proposed; in some cases, the frequency range becomes between $63 \mathrm{~Hz}$ and $8000 \mathrm{~Hz}$ as suggested from the horses' vocalization.

The recommendations that follow, concern the natural sound field but in principle they can also be used where electroacoustic speech reinforcement equipment is introduced and utilized.

Since the sense of reverberation is the most evident attribute that is perceived in a closed space, the reverberation time remains the main parameter to control. To find out the optimal range, it is important to reach a balance, a convergence, between the values for theatres in which animals are excluded (to guarantee the sound quality for the audience) and the spaces where traditionally animals live, including avoiding external noises $(18,19,20)$ which could worsen the sound perception $(21,22,23)$.

A good reverberation for animals as to be as much similar as it is possible to that one that might be found in Nature, as explained above. In the natural world, the early reflections are usually present whereas late reflections are rarely found, because the sound field can be considered as in a "plan-air" and not in a closed space. To avoid frightening animals also eco and eco flutter should be excluded.

Therefore, the requirements to achieve suitable acoustic conditions may vary and a new approach with a response suitable for both speech with music, as in theatre performances, and for animal comfort, is developed. Investigations in this field are few because in modern theatres the presence of animals is usually not allowed.

Recommendations for suitable reverberation time depend on the intended purposes of the room (1). The optimal reverberation time has to make it possible to distinguish the speech and the clarity of music without disturbing the animal sensibility. Because of that, the suggested acceptable upper limit of reverberation time at mid frequencies is equal to $1.3 \mathrm{~s}$.

The reverberation time range has to be also not too low, for different reasons. Even for animals an acoustic response offered without reverberation may sound unattractive, perceiving the space too "dry". Some reverberation effects have to be present to avoid the loose of spatiality i.e. the orientation and equilibrium for the animals. The lower limit has to ensure the acoustic field doesn't become too much similar to that one of a recording studio to ensure the comfort both for the animals and the audience too. The recommended lower limit for the reverberation time is equal to $0.8 \mathrm{~s}$. Both these limits are independent of the volume of the hall.

In identifying the descriptive parameters of this kind of theatre, we have to deal with aspects related to instrumental music, which lead to the choice of the proper values of reverberation rime RT, clarity $\mathrm{C}_{80}$ and strength G. The strength index $\mathrm{G}$ is related with the directivity of the sound source located on the stage and can be used to describe the "plan-air sensation". The reverberation time should not be also too long to guarantee a good speech comprehension related to the values of the acoustic parameters: the definition index $\left(\mathrm{D}_{50}\right)$ and Speech Transmission Index (STI), but also not too short to take into account the musical optimal conditions, controlling the acoustic parameter related to the clarity index $\left(\mathrm{C}_{80}\right)$ for music.

To respect simultaneously both the speech comprehension and the clarity for music, a ratio between the volume and the seats' number is proposed, between the two values 5 and 7 . In those spaces, the $\mathrm{C}_{80}$ value is rarely negative and his interval is usually $0<\mathrm{C}_{80}<4 \mathrm{~dB}$, as in small Italian opera houses having a horseshoe shape (16).

The STI values can be fixed accordingly to the range requested for congress centers. The parameter definition $\mathrm{D}_{50}$ has to be over $50 \%$, as requested for good intelligibility, considering that the values of $\mathrm{D}_{50}>45 \%$ guarantee more than $90 \%$ of the syllables comprehensible, as demonstrated during some psychoacoustic tests in listening room (17), which is requested in congress centers, according to the standard ISO 3382-1, and the predicted values of STI are included between $60 \%$ and $80 \%$ for every seats order, gathering a result classified as good accordingly with the IEC 60268-16 scale quality, provided that external noise is controlled and limited, having installed efficient noise barriers (22).

Moreover, also the center time (CT) has to be considered. This energy-weighted acoustic parameter corresponds to the "center of mass" of the impulse response energy, i.e. it is the time delay the whole energy of the sound field (direct + reverberated), considered as belonging to a single sound wave, takes to reach the measurement point. The optimal range for speech is $0<\mathrm{Ts}<50 \mathrm{~ms}$, for music, can be $50<\mathrm{Ts}<250 \mathrm{~ms}$. In this case the optimal range both for speech and music is proposed as $40<\mathrm{Ts}<100 \mathrm{~ms}$, according to the optimal suggested value of reverberation time, which normally is not higher than $1.3 \mathrm{~s}$.

According to the acoustic quantities for listeners provided in the ISO 3382-1 standard, the sound strength G, which demonstrates the room reflections effect on the sound level, can be considered as near as possible to the value of $1 \mathrm{~dB}$ to guarantee "plan-air" sensations. 
With the hypothesis to maintain a stable acoustic response, independent from the presence of the audience (it means absorbing seats have to be introduced), the main acoustic design recommendations for a theatre to host animals, can be summarized as it follows:

- The ratio volume/seat number has no to exceed the value of 7

- The Reverberation Time range $0.8<\mathrm{RT}<1.3 \mathrm{~s}$ at middle frequencies, the range of frequencies is extended from 63 to $8000 \mathrm{~Hz}$ (a flat profile that decreases from $2000 \mathrm{~Hz}$ due to the air sound absorption is suggested, see table 1)

- $\quad$ The Early Decay Time EDT $1.1 \mathrm{~s}$

- The Center Time Ts proposed as $40<\mathrm{Ts}<100 \mathrm{~ms}$

- The Clarity index range $0<\mathrm{C}_{80}<4 \mathrm{~dB}$

- The Definition index $\mathrm{D}_{50}>45 \%$

- STI between $60 \%$ and $80 \%$ in every order of seats

- $\quad$ Strength $\mathrm{G}>1 \mathrm{~dB}$

- The sound pressure level has no to exceed $75 \mathrm{~dB}$ in order not to irritate the animals

“TABLE 1," the optimal range - Reverberation Time $\mathrm{T}_{30}$

\begin{tabular}{|c|c|c|}
\hline $\mathrm{Hz}$ & Lower value [s] & Upper values [s] \\
\hline 63 & 0.90 & 1.40 \\
\hline 125 & 0.90 & 1.40 \\
\hline 250 & 0.90 & 1.40 \\
\hline 500 & 0.85 & 1.35 \\
\hline 1000 & 0.80 & 1.30 \\
\hline 2000 & 0.75 & 1.25 \\
\hline 4000 & 0.70 & 1.20 \\
\hline 8000 & 0.65 & 1.15 \\
\hline
\end{tabular}

To easily reach these ranges of values, in the following we provide some indications for the acoustic design.

The architectural acoustic quality relies on a successful combination of appropriate acoustic and architectural design. The theatre has to combine effectively two requirements: a large stage for actors and animals and a good audience capacity with excellent aural and visual comfort. Acoustic insulation from external noise, harmonious arrangement of the audience around the performing space, reinforcement of the direct sound through early sound reflections, and suppression of the delayed sound reflections or late reverberation. The harmonious arrangement of the spectators in front and/or around the performance space is within the limits of the human vocal and acoustic range.

The smooth transmission of direct sound, which is reinforced through early, positive sound reflections (from solid sound-reflective surfaces near the actors and small sound-diffusing surfaces near the spectators) is linked to the low reverberation and increased intelligibility of speech due to the reduction of harmful delayed sound reflections and elimination of echo (small diffusive surfaces near the actors and elimination of solid sound-reflective surfaces near the spectators).

The seating of the theatre can be on a stepped arrangement as a cavea, to favor a plain-air sound propagation conditions.

\section{THE CONCEPT DESIGN FOR THE THEATRE "LA STALLA"}

In the following, after having considered the possible trend for the design on the optimization of the acoustic quality for theatres that host animals, a concept for the theatre "La Stalla" is proposed.

In order to define the possible guidelines for designing the acoustics of the theatre, the first inputs are the results of a work done by artists, directors, sculptors, musicians, researchers and philosophers, to design a theatre with a) theatrical equipment, b) the audience placed on a grandstand, and c) a large stage where actors and animals can express their emotions, seek each other, explore fears and curiosities, train each other for respect, show dexterity, reluctance, personal attitudes and disabilities. 


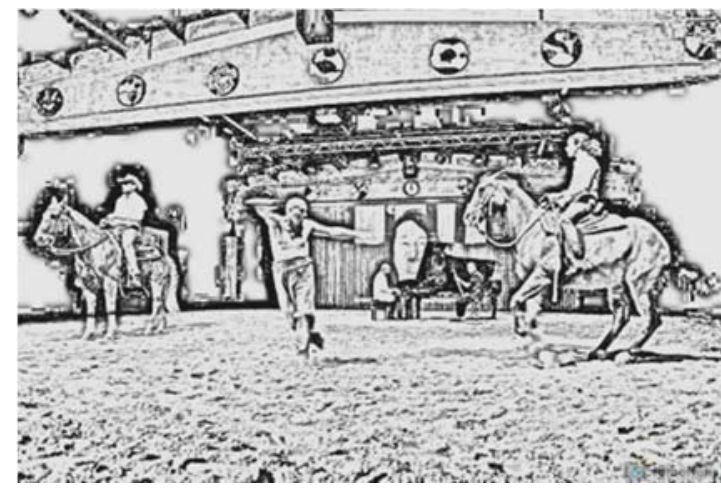

(a)

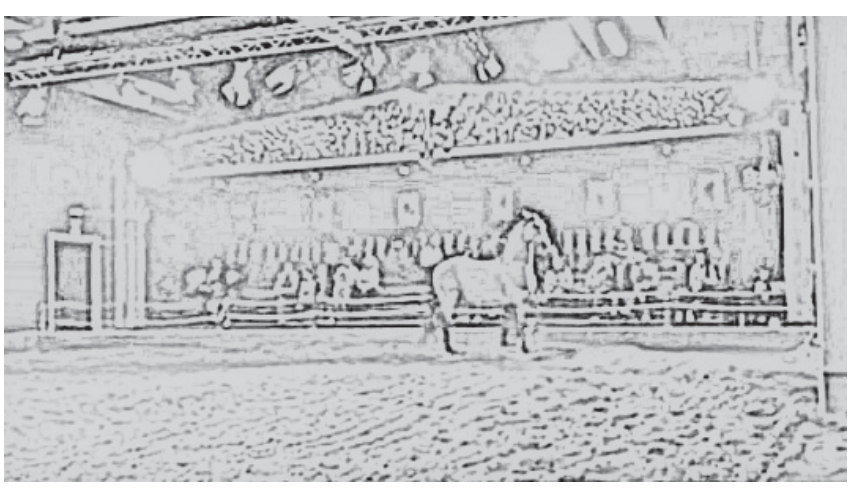

(b)

FIGURE 2. the "Teatro Stalla" concept design sketches: the stage is a sand floor, the stall is distributed on tribunes. The stage has a large area, and it's separated from the stall with a fence.

The stall has to be designed for about 300 people. The shape of the space should be as simple as possible, like a stable, "the Stalla", to make animals feeling at home.

The shape here proposed is positive for the acoustic response, being similar to a shoebox (fig. 2a), i.e. the shape chosen for many congress centers and famous concert halls all around the world. As a consequence of the proposed ratio between volume and seats' number, the gross volume of the theatre should not exceed six times the number of seats, i.e. approximately. $1800 \mathrm{~m}^{3}$. The average height should be approximately $5 \mathrm{~m}$ to ensure early reflections from the lateral walls and ceiling might reach the spectators. The ratio between width and length is about $2 / 3$. The stage should be as large as possible. The stage pavement should be sandy and not raised from the stalls (fig. $2 \mathrm{~b}$ ).

Sharing all these assumptions, it is possible to start the detailed architectural project supported by an acoustic prediction analysis to achieve the acoustic trend previously described.

\section{CONCLUSIONS}

The optimization of the architectural acoustic quality in theatres which host animals, fulfills the comfort both for the audience and for the animals. The architectural elements to influence the room acoustic response are indicated and numerous objective parameters to identify and describe the trend of the requested sound field are described. In particular, their optimal range of values and frequencies is found out.

Since the sense of reverberation is the most evident attribute that is perceived in a closed space, the reverberation time is the main parameter to control. Its optimal range is the result of a balance, a convergence, between the optimal range of values for theatres in which animals are excluded (to guarantee the sound quality for the audience) and for spaces where traditionally animals live.

In this paper it is suggested to maintain a stable acoustic response, independently from the presence of the audience (it means absorbing seats have to be introduced), and the main acoustic design recommendations can be summarized as it follows:

- $\quad$ The ratio volume/seats' number has no to exceed the value 7

- The Reverberation Time optimal range is $0.8<\mathrm{T}_{30}<1.3 \mathrm{~s}$ at middle frequencies (the range of frequencies is extended from 63 to $8000 \mathrm{~Hz}$ )

- The Early Decay Time EDT has no to exceed $1.1 \mathrm{~s}$

- The Center Time CT proposed is $40<\mathrm{Ts}_{\mathrm{s}}<100 \mathrm{~ms}$

- The Clarity index range is $0<\mathrm{C}_{80}<4 \mathrm{~dB}$

- The Definition index is $\mathrm{D}_{50}>45 \%$

- STI between $60 \%$ and $80 \%$ in every order of seats

- Strength is $\mathrm{G}>1 \mathrm{~dB}$ 
In a good acoustic field for animals the early reflections are usually present but late reflections are rare because the field can be considered as in "plein air" and not in a closed space.

Indications about the architectural design are listed to reach easily the acoustic sound field trend for theatres with animals and they are used to identify the concept design of the Teatro Stalla: the chosen ratio between volume and seats' number is decided, the volume has no to exceed six times the number of seats, it means approximately 1800 $\mathrm{m}^{3}$. The shape of the space has to be as simple as possible, like a stable "The Stalla", to let the animals feeling at home.

Through this research the Stalla project development is possible, together with a deep acoustic analysis to find out in details the distribution of the different absorption materials to reach the suggested acoustic sound filed trend i.e. to optimize its architectural acoustic quality.

\section{ACKNOWLEDGMENTS}

This work was carried on within the research of the Bosis Foundation and partially within project n.201594LT3F, funded by PRIN (Programmi di Ricerca Scientifica di Rilevante Interesse Nazionale) of the Italian Ministry of Education, University and Research and the project "SIPARIO - Il Suono: arte Intangibile delle Performing Arts - Ricerca su teatri italiani per l'Opera POR-FESR 2014-20" funded by the Regione Emilia Romagna under EU Commission.

\section{REFERENCES}

1. L. Tronchin, K, Fabbri, Energies, 10(10), 1621, (2017).

2. L. Tronchin, D.J. Knight, International Journal of Historical Archaeology 20(1), 127-145, (2016).

3. E.A. Piana, B. Bianchi, F. Grassi, C. Pedrotti, Building Services Engineering Research and Technology, 39(3),249-262, (2018).

4. L. Tronchin, M. Manfren; P.A. James, Energy, 165(A), 26-40, (2018).

5. L. Tronchin, M. Manfren, L. C. Tagliabue, Sustainable Cities and Society, 27, 296-306, (2016).

6. W.S. Konerding, Anim. Cogn. 14,787-795, (2011).

7. G.H. Waring, Bull. Ecol. Soc. Am. 52,45, (1971).

8. A. Lemasson, A. Boutin, S. Boivin, C., Blois-Heulin, M. Hausberger, Anim. Cogn. 12, 693-704, (2009).

9. L. Proops, K. Mc Comb, D. Reby,. Proc. Natl. Acad. Sci. U. S. A. 106, 947-951, (2009).

10. Y.K. Kim, E.G. Seo, S.S. Lee, E.H., Suh, K.A., Houpt, H.C., Lee, H.J., Lee, S.C., Yeon, C. J. Vet. Med. Sci. 72, 929-933, (2010).

11. J. Ohala, Proceeding of 4th International Conference on Spoken Language 3, 1812-1815, (1996).

12. D. Alberghina, E. Caudullo, N. Bandi, M. Panzera, Journal of Veterinary Behavior 9, 254-257, (2014).

13. A.Farina, L. Tronchin, Acta Acustica United with Acustica, 99, 118-125, (2013).

14. L. Tronchin, Acta Acustica United with Acustica, 99:91-97, (2013).

15. L. Tronchin, M. Manfren, V. Vodola. Applied Sciences 10 (2) 641 (2020).

16. L. Tronchin, M. Manfren, V. Vodola. Applied Sciences 10 (2) 633 (2020).

17. L. Tronchin, F. Merli, M. Manfren, B. Nastasi Building Acoustics, in press doi:10.1177/1351010X20929216 (2020).

18. M. Cairoli. Applied Acoustics 140, 167-177, (2018).

19. M. Cairoli, L. Mazzarella, Applied Acoustics 136, 61-75, (2018).

20. L. Tronchin, F. Merli, M. Manfren, B. Nastasi Building Acoustics, in press doi:10.1177/1351010X20926791 (2020).

21 R. Shimokura, L. Tronchin, A. Cocchi Y. Soeta, Journal of Sound and Vibration, 330 (14), 3526-3537, (2011).

22 L. Tronchin, International Journal of Mechanics, 7 (3), 318-326 (2013).

23 M Caniato, $\cdot$ F Bettarello, L Marsich $\cdot$ A Ferluga, $O$ S Sbaizero, C Schmid, Construction and Building Materials 102 (2015). 